\title{
Wildlife Tuberculosis: A Systematic Review of the Epidemiology in Iberian Peninsula
}

\author{
Nuno Santos ${ }^{1}$, Margarida Correia-Neves ${ }^{1}$, \\ Virgílio Almeida ${ }^{2}$ and Christian Gortázar ${ }^{3}$ \\ ${ }^{1}$ Life and Health Sciences Research Institute (ICVS) \\ School of Health Sciences, University of Minho, Campus de Gualtar, Braga \\ ${ }^{2}$ Centro de Investigação Interdisciplinar em Sanidade Animal - Faculdade de Medicina \\ Veterinária (CIISA/FMV), TULisbon, Pólo Universitário do Alto da Ajuda, Lisbon \\ IIREC National Wildlife Research Institute (CSIC-UCLM-JCCM), Ciudad Real \\ 1,2Portugal \\ ${ }^{3}$ Spain
}

\section{Introduction}

Mycobacterium bovis is the main etiological agent of bovine tuberculosis, infecting many species of wild and domestic mammals and also man. Bovine tuberculosis is a chronic and contagious infectious disease that has been reported to infect wild ungulates, carnivores, marsupials and primates (de Lisle et al., 2002). Bovine tuberculosis (bTB) also occurs worldwide in livestock (Humblet et al., 2009), causing annual economic losses estimated at 3 billion USD in 1995 (Steele, 1995). It remains a serious risk for animal health, and a threat for human health in many developing countries (Etter et al., 2006). Several countries successfully eradicated bovine tuberculosis in livestock through test-and-slaughter and/or abattoir surveillance programs. Yet other countries, using similar strategies, did not achieve eradication and some even face the re-emergence of the disease (Schiller et al., 2010). In Europe for instance, the prevalence of bTB in cattle is increasing in several countries (Gordejo \& Vermeersch, 2006). Moreover current eradication and control programs in livestock in Europe are facing a range of challenges as stamping out is becoming a less attractive option for economic and environmental reasons and due to animal welfare concerns (Whiting, 2003).

Some of the abovementioned difficulties in eradicating bTB in cattle may relate with the occurrence of the disease in wildlife (Schiller et al., 2010). In fact it has been demonstrated that the complete elimination of bTB can be extremely complicated by persistent infection of wild hosts, such as badgers in the United Kingdom, white tailed deer in the United States and brushtail possum in New Zealand (Corner, 2006). The single successful example of bTB eradication in a wildlife host is the Australian case, where it was accomplished through stamping out, which eliminated introduced water buffalo Bubalus arnee, the only maintenance host in that ecosystem, (Corner, 2006). This is not an option when autochthonous, protected or economic and socially valuable species are involved (Artois et al., 2001). In most cases, an integrated control program is needed (Horan et al., 
2008), but this is often hampered by the lack of epidemiological data (Artois et al., 2001; Corner, 2006).

Bovine tuberculosis control programs in cattle are in place for several decades in Iberian Peninsula and consequently incidence has been decreasing (Allepuz et al., 2011; Cunha et al., 2011). However in the last few years incidence has stabilized, or even slightly increased in both Portugal and Spain (Allepuz et al., 2011; Cunha et al., 2011). The role of wildlife hosts in this scenario remains speculative; nevertheless the existence of wildlife reservoirs may compromise the goal of eradication in cattle. Besides livestock, attention should be given to spill-over from wildlife to other domestic animals (e.g. goats and free-ranging pigs) and even to humans, namely hunters and others that handle wild ungulate carcasses (Gortazar et al., 2011b, in press). Wildlife-to-human transmission of M. bovis is hard to prove and no single case has been documented in Iberian Peninsula, but it is known to occur elsewhere (e.g. USA - Wilkins et al., 2008). Bovine tuberculosis is also one of the main infectious diseases affecting the critically endangered Iberian lynx Lynx pardinus, with several freeranging and captive lynx killed by this infection (Millán et al., 2009). Iberian lynx is subject to an intensive multinational conservation program in Iberian Peninsula, which includes releasing captive-bred animals to former range. The persistence of $M$. bovis on the environment and in prey species poses a threat to this conservation action (Millán et al., 2009).

Iberian Peninsula ecosystems display a high degree of human intervention and have experienced some profound changes in the last decades. The most important alterations were a shift from domestic ungulate to wild ungulate production for hunting purposes (Miguel et al. 1999) and an increasing intensification of the later (Vargas et al. 1995). This management of wild ungulate populations aims to increase profits by increasing harvest, translating into increased densities of hunted species. This has been accomplished through introduction/restocking, provision of food and water (mostly during the summer shortage), fencing and sometimes even medication (Miguel et al. 1999, Gortázar et al., 2006). All these changes have potential implications on bTB epidemiology (Gortázar et al., 2006).

In the Iberian Peninsula, ungulates such as the wild boar Sus scrofa and the red deer Cervus elaphus have been recognized as the most important maintenance hosts for wildlife tuberculosis (Gortázar et al., 2011b). Nevertheless other species have also been identified as locally non-negligible hosts, such as the fallow deer Dama dama and the badger Meles meles (Gortázar et al., 2011b; Balseiro et al., 2011). Several other species of ungulates and carnivores were also found infected (Rodriguez et al., 2010). This situation fits the definition of a multihost pathogen within a multi-species ecosystem (Renwick et al., 2007; Gortázar et al., in press), in which pathogen persistence and spread is dependent on the density of each maintenance host species and also on the effective interspecies contact rate (dependent on the ecology of each species).

Research on host-pathogen interaction usually deals with single-host single-pathogen systems, where disease persistence depends solely on the intra-species transmission rate (Tompkins et al., 2001). If transmission is density-dependent, then population thresholds for disease invasion and persistence are expected and have been described (Swinton et al., 2001). By contrast, in multi-host pathogens systems, disease persistence is dependent on both intra and inter-species transmission rates and densities of several host species (Renwick et al., 2007). Moreover, these rates depend on pathological, epidemiological, ecological and behavioural factors (Corner, 2006). 
In such a complex epidemiological setting, it is imperative to determine the precise role of each host species in pathogen maintenance before comprehensive control measures are undertaken. Much has been investigated in the last decade regarding wildlife tuberculosis epidemiology in Iberian Peninsula. In order to contribute to understanding the mechanisms underlying wildlife tuberculosis persistence in the multi-host ecosystems of this region, under widely different ecological and management pressures, we report a systematic bibliographic review on this subject. The aim of this review was to survey the peer-reviewed literature for evidence of the: $i$ ) epidemiological status of each host species; ii) determinants of wildlife tuberculosis occurrence; iii) geographical structuring of wildlife tuberculosis in the Iberian Peninsula; iv) time trends in wildlife tuberculosis occurrence.

\section{Methods}

We conducted a systematic bibliographic review for epidemiological studies on tuberculosis in wildlife in Iberian Peninsula by searching MEDLINE/PubMed, up to the 31 ${ }^{\text {st }}$ of August 2011, using MeSH and keywords: "Mycobacterium bovis", "Mycobacterium caprae", "wild boar", "deer", "epidemiology", "Iberian Peninsula", "Portugal" and "Spain". Combinations used were: ("Portugal" OR "Spain") AND ("Mycobacterium bovis" OR "Mycobacterium caprae"), ("Mycobacterium bovis" OR "Mycobacterium caprae") AND "wild boar" AND "epidemiology" and ("Mycobacterium bovis" OR "Mycobacterium caprae") AND "deer" AND "epidemiology". Abstracts were selected according to their relevancy and excluded if dealing exclusively with laboratory or pathology investigations, domestic species or humans or other geographical regions. Articles were reviewed in full text.

For each article, information about the type of epidemiological study and study design, sample size and sampling methodology, screening and diagnostic tests used, prevalence rate, time frame of the study, study areas, characteristics of the populations studied, risk factors identified and host epidemiological status was summarized and presented in table format for easy comparison. Due to their idiosyncrasies, molecular epidemiology articles were characterized differently according to the number of isolates studied, genotyping technique, mycobacterial species reported, number of genotypes found, host and geographical clustering of genotypes and study areas. Due to differing methodologies and sometimes incomplete reporting of results, meta-analysis was not applicable except for a small number of studies.

For the purpose of this review, wildlife tuberculosis was defined according to the OIE definition of bovine tuberculosis, but Mycobacterium caprae was also considered etiological agent, besides $M$. bovis.

\section{Results}

The bibliographic search yielded 286 articles. Initially, title and abstracts were reviewed and 247 articles excluded because they deal only with laboratory/pathology investigations $(n=74)$, domestic animals $(n=41)$, humans $(n=50)$, other geographical regions $(n=79)$, or were review/model articles $(n=3)$. Full text papers were then reviewed and further 6 papers were excluded because they focused exclusively on laboratory/pathology investigations. Therefore 33 articles were selected as of interest to the present review. 


\begin{tabular}{|c|c|c|c|c|c|c|c|c|c|}
\hline Reference & Type & \begin{tabular}{|c|} 
Sampling \\
strategy
\end{tabular} & $\begin{array}{c}\text { Sample } \\
\mathrm{n}\end{array}$ & $\begin{array}{c}\text { Screening } \\
\text { test }\end{array}$ & $\begin{array}{c}\text { Diagnostic } \\
\text { test }\end{array}$ & $\begin{array}{l}\text { Time frame } \\
\& \text { tendency }\end{array}$ & \begin{tabular}{|c}
$\begin{array}{c}\text { Prevalence } \\
\text { (rate) }\end{array}$ \\
\end{tabular} & Fencing & $\begin{array}{c}\text { Study } \\
\text { areas }\end{array}$ \\
\hline $\begin{array}{c}\text { Aranaz et al. } \\
(2004)\end{array}$ & SU & $\begin{array}{l}\text { Targeted } \\
\text { (hunted) }\end{array}$ & 96 & & $\mathrm{BC}$ & & $\begin{array}{c}51 \\
(53,1 \%)\end{array}$ & MX & $\begin{array}{c}7 \text { area } \\
\text { SW Spain }\end{array}$ \\
\hline $\begin{array}{l}\text { Acevedo- } \\
\text { Whitehouse } \\
\text { et al. (2005) }\end{array}$ & CS & $\begin{array}{l}\text { Targeted } \\
\text { (hunted) }\end{array}$ & 175 & & $\mathrm{BC}$ & $2000-2003$ & $\begin{array}{c}82 \\
(47 \%)\end{array}$ & MX & $\begin{array}{c}7 \text { areas } \\
\text { SW Spain }\end{array}$ \\
\hline $\begin{array}{c}\text { Parra et al. } \\
(2005)\end{array}$ & CS & $\begin{array}{l}\text { Scanning } \\
\text { (hunted) }\end{array}$ & 112 & MI & $\mathrm{BC}$ & & 112 & FE & \begin{tabular}{|l|}
1 region \\
W Spain
\end{tabular} \\
\hline $\begin{array}{l}\text { de Mendoza } \\
\text { et al. (2006) }\end{array}$ & CS & $\begin{array}{l}\text { Scanning } \\
\text { (hunted) }\end{array}$ & 8.478 & MI & $\mathrm{BC}$ & $\begin{array}{l}\text { 1992-2004 } \\
\text { increasing }\end{array}$ & $\begin{array}{c}333 \\
(3,92 \%)\end{array}$ & MX & $\begin{array}{c}1 \text { area } W \\
\text { Spain }\end{array}$ \\
\hline $\begin{array}{c}\text { Parra et al. } \\
(2006)\end{array}$ & CS & $\begin{array}{l}\text { Scanning } \\
\text { (hunted) }\end{array}$ & 34.582 & MI & $\mathrm{BC}$ & $\begin{array}{l}1997-2002 \\
\text { increasing }\end{array}$ & $\begin{array}{c}625 \\
(1,81 \%) \\
\end{array}$ & MX & \begin{tabular}{|l|}
1 region \\
W Spain
\end{tabular} \\
\hline $\begin{array}{c}\text { Vicente } \text { et al. } \\
\text { (2006a) }\end{array}$ & CS & $\begin{array}{l}\text { Targeted } \\
\text { (hunted) }\end{array}$ & 1.060 & & $\begin{array}{c}\text { GP } \\
\text { BC } \\
\text { (not all) } \\
\end{array}$ & 1999-2004 & $\begin{array}{c}(42,51 \%, \\
\text { mean } \\
\text { estate rate })\end{array}$ & MX & $\begin{array}{c}57 \text { areas } \\
\text { SW Spain }\end{array}$ \\
\hline $\begin{array}{l}\text { Vicente } \text { et al. } \\
\quad(2006 b)\end{array}$ & CS & $\begin{array}{l}\text { Targeted } \\
\text { (hunted) }\end{array}$ & 412 & & $\begin{array}{c}\text { GP } \\
\text { BC } \\
\text { (not all) } \\
\end{array}$ & 1999-2004 & $\begin{array}{c}(18,2 \%- \\
100 \%)\end{array}$ & FE & $\begin{array}{c}19 \text { area } \\
\text { SW Spain }\end{array}$ \\
\hline $\begin{array}{c}\text { Gortázar et al. } \\
(2008)\end{array}$ & CS & $\begin{array}{c}\text { Targeted } \\
\text { (culled) }\end{array}$ & 124 & & $\mathrm{BC}$ & 2006-2007 & $\begin{array}{c}65 \\
(52,4 \%)\end{array}$ & FR & $\begin{array}{c}1 \text { area } \\
\text { SW Spain }\end{array}$ \\
\hline $\begin{array}{c}\text { Romero } \text { et al. } \\
(2008)\end{array}$ & SU & $\begin{array}{c}\text { Targeted } \\
\text { (culled) }\end{array}$ & 214 & & $\mathrm{BC}$ & 1998-2003 & $\begin{array}{c}60 \\
(28,0 \%)\end{array}$ & FR & $\begin{array}{c}1 \text { area } \\
\text { SW Spain }\end{array}$ \\
\hline $\begin{array}{l}\text { Santos et al. } \\
\quad(2009)\end{array}$ & CS & $\begin{array}{l}\text { Targeted } \\
\text { (hunted) }\end{array}$ & 162 & & $\mathrm{BC}$ & $2005-2007$ & $\begin{array}{c}18 \\
(11,1 \%)\end{array}$ & FR & \begin{tabular}{|c|}
8 areas \\
South- \\
central \\
Portugal
\end{tabular} \\
\hline $\begin{array}{c}\text { Cunha et al. } \\
\text { (2011) }\end{array}$ & SU & $\begin{array}{l}\text { Scanning } \\
\text { (hunted) }\end{array}$ & 343 & MI & BC & $2002-2010$ & $(63 \%)$ & MX & \begin{tabular}{|c|}
$\begin{array}{c}\text { Several } \\
\text { areas } \\
\text { across } \\
\text { Portugal }\end{array}$ \\
\end{tabular} \\
\hline $\begin{array}{c}\text { Gortázar et al. } \\
(2011 \mathrm{a})\end{array}$ & CS & $\begin{array}{c}\text { Targeted } \\
\text { (culled) }\end{array}$ & 124 & & $\mathrm{BC}$ & 2006-2007 & $\begin{array}{c}62 \\
(50 \%) \\
\end{array}$ & FR & $\begin{array}{c}1 \text { area } \\
\text { SW Spain }\end{array}$ \\
\hline $\begin{array}{l}\text { Pinto et al. } \\
\text { (2011) }\end{array}$ & CS & $\begin{array}{l}\text { Targeted } \\
\text { (hunted) }\end{array}$ & 132 & GP & $\mathrm{BC}$ & 2008-2009 & $\begin{array}{c}21 \\
(15,9 \%)\end{array}$ & MX & \begin{tabular}{|c|}
1 area \\
Central \\
Portugal
\end{tabular} \\
\hline
\end{tabular}

Table 1. Studies dealing with wild boar included in the analysis. Classification: SU - survey; CS - cross sectional study; CC - case-control study; Screening/diagnostic test: MI - official meat inspection scheme; GP - gross pathology; BC - bacteriological culture; SE - serology; Fencing: FR - free-ranging populations; FE - fenced populations; MX - mixed free-ranging and fenced populations.

\subsection{Characterization of published articles}

Investigation of bTB epidemiology in wild boar and red deer (most often studied hosts) are mostly cross-sectional (11/14), the rest being surveys (Tables 1-2). Most studies opt for 
targeted surveillance on hunted (6/14) or culled (3/14) animals, the rest relying on scanning surveillance in routine meat inspection schemes for detection of macroscopic lesions-like lesions (Table 1-2). The mean number of animals studied in targeted-design studies is 278 for wild boar ( $n=9$, range 96-1.060) and 401 for red deer $(n=6$, range 95-1.368). Thirteen out of fourteen studies use bacteriological culture as the diagnostic test. Nevertheless most of them (9/14) also include a previous screening test (usually gross pathology or routine meat inspection schemes), followed by bacteriological culture when macroscopic lesions were observed (Table 1-2).

As regards studies on other host species (ungulates and carnivores), 5/14 are case reports, 6/14 surveys while 3/14 are cross sectional studies (Table 3). Five out of twelve studies rely on passive surveillance of haphazardly found carcasses and 3/12 on targeted surveillance of purposefully trapped animals. Most of these studies deal with carnivore species. As expected regarding novel host species, 3/12 studies are case reports (Table 3). Mean number of animals studied in survey studies is 105 for fallow deer $(n=4$, range 89134), 63 for badger ( $n=3$, range 2-157) and 15 for Iberian lynx ( $n=5$, range 1-39). Most other species (Table 5) are dealt in single studies, usually as case reports. Serologic tests were used in 3/9 studies investigating other host species, such as Barbary sheep and carnivores (Table 3).

\subsection{Prevalence rates}

For the wild boar populations surveyed by targeted-design studies using bacteriological culture as diagnostic test on all animals $(n=6)$, prevalence rates ranged $0,11-0,53$, with a meta prevalence rate of 0,36 (Table 5). Including all studies, regardless of design, prevalence rates ranged 0,18-1 (Table 1). For the red deer populations surveyed by targeted-design studies using bacteriological culture as diagnostic test on all animals samples $(n=3)$, prevalence rates ranged 0,02-0,27, with a meta prevalence rate of 0,21 (Table 5). Including all studies, regardless of design, prevalence rates ranged 0,01-0,44 (Table 2). For the fallow deer populations surveyed by targeted-design studies using bacteriological culture as diagnostic test on all animals samples $(n=4)$, prevalence rates ranged $0,13-0,67$, with a meta prevalence rate of 0,28 (Table 5). For other host species, the sample size and/or the study design do not allow meta analysis.

\subsection{Trends}

Few studies address or allow addressing the time trend of bTB prevalence rates. In Doñana, bTB was not detected in targeted wildlife health surveillance until 1990's, when the population of cattle greatly increased, while in 2000's high prevalence rates were found in all ungulate species (Gortázar et al., 2008). In fact, prevalence rates in this area increased from 1998-2003 to 2006-2007 by $100 \%$ in wild boar and 50\% in red deer (Gortázar et al., 2011b). In Extremadura region, West-central Spain, prevalence rates detected in routine meat inspection schemes steadily raised from 1994-2004, while not detected in 1992-1993 (de Mendonza et al., 2006). One study area in South-eastern Portugal showed an increase in $M$. bovis infection rates in wild boar from 0,46 in 2005/06 (Santos et al., 2009) to 0,78 in 2009/11 (Santos et al., unpublished data). 


\begin{tabular}{|c|c|c|c|c|c|c|c|c|c|}
\hline Reference & Type & $\begin{array}{l}\text { Sampling } \\
\text { strategy }\end{array}$ & $\begin{array}{c}\text { Sample } \\
\mathrm{n}\end{array}$ & $\begin{array}{c}\text { Screening } \\
\text { test }\end{array}$ & $\begin{array}{c}\text { Diagnostic } \\
\text { test }\end{array}$ & $\begin{array}{c}\text { Time } \\
\text { frame \& } \\
\text { tendency }\end{array}$ & $\begin{array}{c}\text { Prevalence } \\
\text { (rate) }\end{array}$ & Fencing & $\begin{array}{l}\text { Study } \\
\text { areas }\end{array}$ \\
\hline $\begin{array}{l}\text { Aranaz et } \\
\text { al. (2004) }\end{array}$ & SU & $\begin{array}{l}\text { Targeted } \\
\text { (hunted) }\end{array}$ & 108 & & $\mathrm{BC}$ & & $\begin{array}{c}26 \\
(24,1 \%) \\
\end{array}$ & MX & $\begin{array}{c}5 \text { areas } \\
\text { SW Spain }\end{array}$ \\
\hline $\begin{array}{c}\text { Parra et al. } \\
(2005)\end{array}$ & CS & $\begin{array}{l}\text { Scanning } \\
\text { (hunted) }\end{array}$ & 59 & MI & $\mathrm{BC}$ & & 59 & $\mathrm{FE}$ & $\begin{array}{l}1 \text { region } \\
\text { W Spain }\end{array}$ \\
\hline $\begin{array}{c}\text { de } \\
\text { Mendoza } \\
\text { et al. (2006) }\end{array}$ & CS & $\begin{array}{l}\text { Scanning } \\
\text { (hunted) }\end{array}$ & 36.144 & MI & $\mathrm{BC}$ & $\begin{array}{l}\text { 1992-2004 } \\
\text { increasing }\end{array}$ & $\begin{array}{c}394 \\
(1,09 \%)\end{array}$ & MX & $\begin{array}{c}1 \text { area } W \\
\text { Spain }\end{array}$ \\
\hline $\begin{array}{c}\text { Parra et al. } \\
(2006)\end{array}$ & CS & $\begin{array}{l}\text { Scanning } \\
\text { (hunted) }\end{array}$ & 50.009 & MI & $\mathrm{BC}$ & $\begin{array}{l}1997-2002 \\
\text { increasing }\end{array}$ & $\begin{array}{c}591 \\
(1,18 \%) \\
\end{array}$ & MX & $\begin{array}{l}1 \text { region } \\
\text { W Spain }\end{array}$ \\
\hline $\begin{array}{l}\text { Vicente et } \\
\text { al. }(2006 \mathrm{a})\end{array}$ & CS & $\begin{array}{l}\text { Targeted } \\
\text { (hunted) }\end{array}$ & 1.368 & & $\begin{array}{c}\text { GP } \\
\text { BC } \\
\text { (not all) }\end{array}$ & 1999-2004 & $\begin{array}{c}(13,71 \% \\
\text { mean rate })\end{array}$ & MX & $\begin{array}{c}21 \text { areas } \\
\text { SW Spain }\end{array}$ \\
\hline $\begin{array}{l}\text { Vicente } e t \\
\text { al. }(2006 \mathrm{~b})\end{array}$ & CS & $\begin{array}{l}\text { Targeted } \\
\text { (hunted) }\end{array}$ & 574 & & $\begin{array}{c}\mathrm{GP} \\
\text { BC } \\
\text { (not all) }\end{array}$ & 1999-2004 & $(0-44,0 \%)$ & FE & $\begin{array}{c}19 \text { areas } \\
\text { SW Spain }\end{array}$ \\
\hline $\begin{array}{c}\text { Gortázar et } \\
\text { al. (2008) }\end{array}$ & CS & $\begin{array}{c}\text { Targeted } \\
\text { (culled) }\end{array}$ & 95 & & $\mathrm{BC}$ & 2006-2007 & $\begin{array}{c}26 \\
(27,4 \%)\end{array}$ & FR & $\begin{array}{c}1 \text { area } S W \\
\text { Spain }\end{array}$ \\
\hline $\begin{array}{c}\text { Romero et } \\
\text { al. (2008) }\end{array}$ & SU & $\begin{array}{c}\text { Targeted } \\
\text { (culled) }\end{array}$ & 168 & & $\mathrm{BC}$ & 1998-2003 & $\begin{array}{c}26 \\
(15,5 \%)\end{array}$ & FR & $\begin{array}{c}1 \text { area } S W \\
\text { Spain }\end{array}$ \\
\hline $\begin{array}{l}\text { Castillo et } \\
\text { al. (2010) }\end{array}$ & CS & $\begin{array}{l}\text { Scanning } \\
\text { (hunted) }\end{array}$ & 551 & MI & $\mathrm{BC}$ & 2007-2009 & $\begin{array}{c}28 \\
(5,1 \%)\end{array}$ & MX & $\begin{array}{c}2 \text { areas } \\
\text { SW Spain }\end{array}$ \\
\hline $\begin{array}{l}\text { Cunha et } \\
\text { al. (2011) }\end{array}$ & SU & $\begin{array}{l}\text { Scanning } \\
\text { (hunted) }\end{array}$ & $\begin{array}{c}544 \\
\text { samples } \\
\text { with } \\
\text { lesion } \\
\end{array}$ & MI & $\mathrm{BC}$ & 2002-2010 & $(51 \%)$ & MX & $\begin{array}{c}\text { Several } \\
\text { areas } \\
\text { across } \\
\text { Portugal }\end{array}$ \\
\hline $\begin{array}{c}\text { Gortázar et } \\
\text { al. (2011a) }\end{array}$ & CS & $\begin{array}{l}\text { Targeted } \\
\text { (culled) }\end{array}$ & 95 & & $\mathrm{BC}$ & 2006-2007 & $\begin{array}{c}24 \\
(25,3 \%)\end{array}$ & FR & $\begin{array}{l}1 \text { study } \\
\text { area SW } \\
\text { Spain }\end{array}$ \\
\hline $\begin{array}{c}\text { Pinto et al. } \\
\text { (2011) }\end{array}$ & CS & $\begin{array}{l}\text { Targeted } \\
\text { (hunted) }\end{array}$ & 339 & GP & $\mathrm{BC}$ & 2008-2009 & $\begin{array}{c}35 \\
(10,3 \%)\end{array}$ & MX & $\begin{array}{c}1 \text { area } \\
\text { Central } \\
\text { Portugal }\end{array}$ \\
\hline
\end{tabular}

Table 2. Studies dealing with red deer included in the analysis. Classification: SU - survey; CS - cross sectional study; CC - case-control study; Screening/diagnostic test: MI - official meat inspection scheme; GP - gross pathology; BC - bacteriological culture; SE - serology; Fencing: FR - free-ranging populations; FE - fenced populations; MX - mixed free-ranging and fenced populations. 


\begin{tabular}{|c|c|c|c|c|c|c|c|c|}
\hline Reference & Type & $\begin{array}{l}\text { Sampling } \\
\text { strategy }\end{array}$ & $\begin{array}{c}\text { Sample } \\
\text { n }\end{array}$ & $\begin{array}{c}\text { Diagnostic } \\
\text { test }\end{array}$ & $\begin{array}{l}\text { Time } \\
\text { frame }\end{array}$ & $\begin{array}{l}\text { Prevalence } \\
\text { (rate) }\end{array}$ & Fencing & $\begin{array}{l}\text { Study } \\
\text { areas }\end{array}$ \\
\hline $\begin{array}{c}\text { Briones et al. } \\
(2000)\end{array}$ & CR & & 1 Iberian lynx & $\mathrm{BC}$ & & 1 & FR & $\begin{array}{l}1-S W \\
\text { Spain }\end{array}$ \\
\hline $\begin{array}{l}\text { Pérez et al. } \\
(2001)\end{array}$ & CR & & 1 Iberian lynx & $\mathrm{BC}$ & & 1 & FR & $\begin{array}{l}1-S W \\
\text { Spain }\end{array}$ \\
\hline \multirow{2}{*}{$\begin{array}{c}\text { Aranaz et al. } \\
\qquad(2004)\end{array}$} & \multirow{2}{*}{ SU } & $\begin{array}{l}\text { Targeted } \\
\text { (hunted) }\end{array}$ & 89 fallow deer & \multirow{2}{*}{$\mathrm{BC}$} & & $\begin{array}{c}60 \text { fallow deer } \\
(67,4 \%)\end{array}$ & \multirow{2}{*}{ MX } & \multirow{2}{*}{$\begin{array}{l}2 \text { area } \\
\text { SW } \\
\text { Spain }\end{array}$} \\
\hline & & $\begin{array}{l}\text { Scanning } \\
\text { (carcasses) }\end{array}$ & 4 Iberian lynx & & & 3 Iberian lynx & & \\
\hline $\begin{array}{l}\text { Atance et al. } \\
\quad(2005)\end{array}$ & SU & $\begin{array}{l}\text { Scanning } \\
\text { (carcasses) }\end{array}$ & $\begin{array}{c}7 \text { red fox } \\
2 \text { mongoose } \\
2 \text { genets } \\
1 \text { Iberian lynx } \\
4 \text { mustelids }\end{array}$ & $\mathrm{BC}$ & & 1 red fox & FR & $\begin{array}{l}1 \text { area } \\
\text { SW } \\
\text { Spain }\end{array}$ \\
\hline $\begin{array}{l}\text { Atance et al. } \\
\qquad(2006)\end{array}$ & SU & $\begin{array}{l}\text { Targeted } \\
\text { (trapped) }\end{array}$ & $\begin{array}{l}118 \text { red fox } \\
5 \text { mongoose } \\
4 \text { genets } \\
\text { 39 Iberian lynx } \\
32 \text { mustelids }\end{array}$ & $\begin{array}{l}\text { SE (ELISA } \\
\text { MPB70) }\end{array}$ & & $\begin{array}{l}5 \text { red fox }(4 \%) \\
1 \text { Iberian lynx } \\
\quad(3 \%) \\
7 \text { badger }(23 \%)\end{array}$ & FR & $\begin{array}{l}1 \text { area } \\
\text { SW } \\
\text { Spain }\end{array}$ \\
\hline $\begin{array}{c}\text { Gortázar et al. } \\
\text { (2008) }\end{array}$ & CS & $\begin{array}{c}\text { Targeted } \\
\text { (culled) }\end{array}$ & 97 fallow deer & $\mathrm{BC}$ & $\begin{array}{l}2006- \\
2007\end{array}$ & $\begin{array}{c}18 \\
(18,5 \%)\end{array}$ & FR & $\begin{array}{c}1 \text { area } \\
\text { SW } \\
\text { Spain }\end{array}$ \\
\hline $\begin{array}{l}\text { Millán et al. } \\
\text { (2008) }\end{array}$ & CR & & 1 red fox & $\mathrm{BC}$ & & 1 & FR & $\begin{array}{c}1 \text { area } \\
\text { SW } \\
\text { Spain }\end{array}$ \\
\hline \multirow{3}{*}{$\begin{array}{l}\text { Romero et al. } \\
\qquad(2008)\end{array}$} & \multirow{3}{*}{ SU } & $\begin{array}{l}\text { Targeted } \\
\text { (culled) }\end{array}$ & 134 fallow deer & \multirow{3}{*}{$\mathrm{BC}$} & \multirow{3}{*}{$\begin{array}{l}1998- \\
2003\end{array}$} & $\begin{array}{c}17 \\
(12,7 \%) \\
\end{array}$ & \multirow{3}{*}{ FR } & \multirow{3}{*}{$\begin{array}{l}1 \text { area } \\
\text { SW } \\
\text { Spain }\end{array}$} \\
\hline & & \multirow{2}{*}{$\begin{array}{l}\text { Scanning } \\
\text { (carcasses) }\end{array}$} & 10 Iberian lynx & & & $4(40 \%)$ & & \\
\hline & & & 5 red fox & & & $2(40 \%)$ & & \\
\hline $\begin{array}{l}\text { Sobrino et al. } \\
\qquad(2008)\end{array}$ & CR & & 1 badger & $\mathrm{BC}$ & & 1 & FR & $\begin{array}{l}1 \text { area } \\
\text { SW } \\
\text { Spain }\end{array}$ \\
\hline $\begin{array}{c}\text { Candela et al. } \\
\text { (2009) }\end{array}$ & CS & $\begin{array}{l}\text { Targeted } \\
\text { (hunted) }\end{array}$ & 61 Barbary sheep & $\begin{array}{c}\text { SE } \\
\text { (icELISA } \\
\text { MPB70) } \\
\end{array}$ & 1999 & $(50 \%)$ & FR & $\begin{array}{c}1 \text { area } \\
\text { SE Spain }\end{array}$ \\
\hline $\begin{array}{l}\text { Millán et al. } \\
\text { (2009) }\end{array}$ & SU & $\begin{array}{l}\begin{array}{l}\text { Targeted } \\
\text { (trapped) }\end{array} \\
\text { Scanning } \\
\text { (carcasses) }\end{array}$ & $\begin{array}{l}26 \text { Iberian lynx } \\
33 \text { red fox } \\
24 \text { mongoose } \\
10 \text { gennet } \\
2 \text { badger }\end{array}$ & $\begin{array}{c}\text { BC } \\
\text { PCR } \\
\text { SE (cELISA } \\
\text { MPB70) }\end{array}$ & $\begin{array}{l}2004- \\
2006\end{array}$ & $\begin{array}{l}\text { SE: } 1 \text { red fox } \\
1 \text { mongoose } \\
2 \text { badger } \\
\text { BC: } 2 \text { red fox } \\
2 \text { Iberian lynx }\end{array}$ & FR & $\begin{array}{l}2 \text { area } \\
\text { SW } \\
\text { Spain }\end{array}$ \\
\hline $\begin{array}{c}\text { Balseiro et al. } \\
(2009)\end{array}$ & CR & & 1 roe deer & $\begin{array}{l}\text { PCR } \\
\text { IHC }\end{array}$ & & 1 & FR & \begin{tabular}{|c}
1 area $\mathrm{N}$ \\
Spain
\end{tabular} \\
\hline $\begin{array}{c}\text { Gortázar et al. } \\
\text { (2011a) }\end{array}$ & CS & $\begin{array}{l}\text { Targeted } \\
\text { (culled) }\end{array}$ & 100 fallow deer & $\mathrm{BC}$ & $\begin{array}{l}2006- \\
2007\end{array}$ & $\begin{array}{c}21 \\
(21 \%)\end{array}$ & FR & $\begin{array}{c}1 \text { area } \\
\text { SW } \\
\text { Spain }\end{array}$ \\
\hline $\begin{array}{l}\text { Balseiro et al. } \\
\quad(2011)\end{array}$ & SU & $\begin{array}{c}\text { Targeted } \\
\text { (trapped) } \\
\text { Passive } \\
\text { (carcasses) }\end{array}$ & $\begin{array}{l}157 \text { badger (121 } \\
\text { found dead, } 36 \\
\text { trapped) }\end{array}$ & $\mathrm{BC}$ & $\begin{array}{l}2006- \\
2010\end{array}$ & $\begin{array}{c}8 \text { found dead } \\
(6,6 \%) \\
0 \text { trapped }\end{array}$ & FR & $\begin{array}{c}\text { Several } \\
\text { areas } \\
\text { across } \\
\text { Spain }\end{array}$ \\
\hline
\end{tabular}

Table 3. Studies dealing with other host species included in the analysis. Classification: SU - survey; CS - cross sectional study; CC - case-control study; Screening/diagnostic test: MI - official meat inspection scheme; GP - gross pathology; BC - bacteriological culture; SE - serology; IHC - immunohistochemistry; ELISA - enzyme-linked immune serum assay; Fencing: FR - free-ranging populations; FE - fenced populations; MX - mixed free-ranging and fenced populations. 


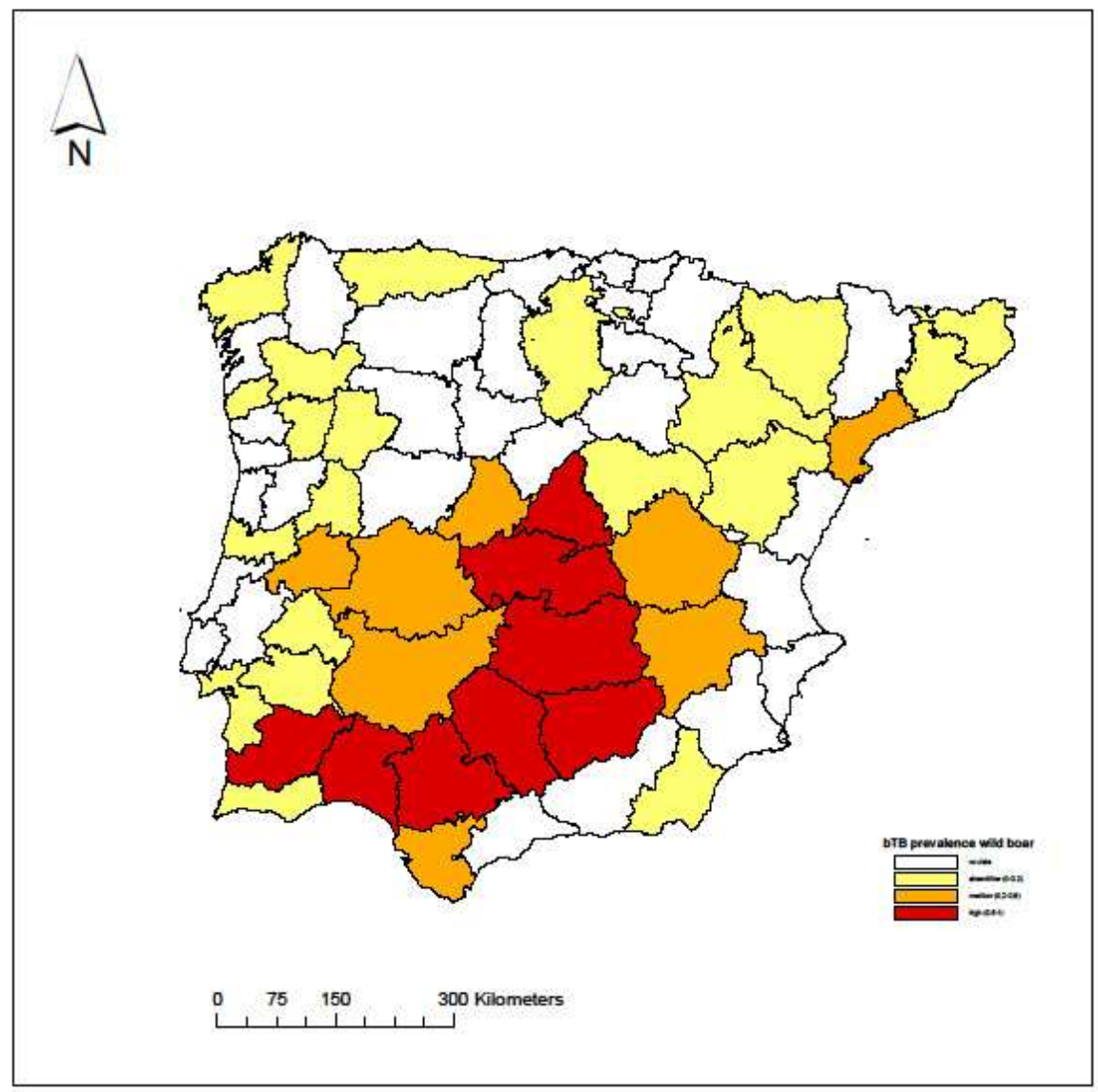

Fig. 1. Map displaying reported prevalence rates for bTB in the wild boar by administrative divisions of Iberian Peninsula (provinces in Spain, districts in Portugal). Bacteriological culture data (Aranaz et al., 2004; de Mendoza et al., 2006; Vicente et al., 2006a; Gortázar et al., 2008; Santos et al., 2009; Pinto et al., 2011) and serology data (Boadella et al., 2011; Santos et al., unpublished data) combined. The highest recorded prevalence for each administrative division is shown.

Again, few published articles address or allow addressing the geographical trend in bTB prevalence rates. In South-central Spain, an area roughly corresponding to Sierra Morena and Montes de Toledo was shown to have high prevalence rates, which declined towards the periphery of the area (Vicente et al., 2006a). In Doñana, wild boar and red deer show an increasing South-North gradient in prevalence rates (Gortázar et al., 2008). In Portugal, bTB was not detected in western regions, while present in the eastern portion of the country (Santos et al., 2009). Also in Eastern-central Portugal, wild boar and red deer populations show an increasing North-South gradient in prevalence rates (Pinto et al., 2011). In Southcentral Spain, lack of geographical autocorrelation in prevalence rates was reported (Vicente et al., 2006b). 


\subsection{Determinant factors of disease}

Several risk and protective factors for bTB in both wild boar and red deer have been identified (Table 4). Most of the identified risk factors relate to host and other sympatric host's population factors, but also to environmental, management and historical factors. On the other hand, protective factors are mainly associated with environmental variables (Table 4). Notably, only one study has identified fencing, feeding and watering of wild ungulate populations as risk factors.

\begin{tabular}{|c|c|c|c|}
\hline \multicolumn{2}{|c|}{ Determinants of disease } & \multirow[t]{2}{*}{ Wild boar } & \multirow[t]{2}{*}{ Red deer } \\
\hline & $\begin{array}{l}\text { Type of risk } \\
\text { factor }\end{array}$ & & \\
\hline \multirow[t]{5}{*}{ Risk factors } & Host population & $\begin{array}{l}\text { Reproductive season } \\
\text { Age } \\
\text { Sex } \\
\text { bTB prevalence rate in } \\
\text { sympatric wild boar } \\
\text { Wild boar abundance }\end{array}$ & $\begin{array}{l}\text { Reproductive season } \\
\text { Age } \\
\text { Sex } \\
\text { bTB prevalence rate in sympatric } \\
\text { red deer }\end{array}$ \\
\hline & Other hosts & $\begin{array}{l}\text { Red deer presence } \\
\text { Red deer abundance } \\
\text { bTb prevalence rate in } \\
\text { sympatric red deer }\end{array}$ & $\begin{array}{l}\text { bTb prevalence rate in sympatric } \\
\text { wild boar }\end{array}$ \\
\hline & Environmental & Agro forestry land cover & \\
\hline & Management & $\begin{array}{l}\text { Aggregation at watering } \\
\text { sites }\end{array}$ & $\begin{array}{l}\text { Aggregation of wild boar at } \\
\text { watering and feeding sites } \\
\text { Fencing } \\
\text { Supplementary feeding } \\
\text { Presence water ponds } \\
\text { Presence of livestock }\end{array}$ \\
\hline & Historical & $\begin{array}{l}\text { Past cattle density } \\
\text { Distance to historical } \\
\text { refuges }\end{array}$ & Past cattle density \\
\hline $\begin{array}{l}\text { Protective } \\
\text { factors }\end{array}$ & All & $\begin{array}{l}\text { Shrub land cover } \\
\text { Distance to freshwater } \\
\text { Sparse forestry land cover } \\
\text { Genetic variability }\end{array}$ & Distance to freshwater \\
\hline
\end{tabular}

Table 4. Determinant factors of bTB occurrence identified in wild boar and red deer epidemiological studies in the Iberian Peninsula.

\subsection{Host epidemiological status}

Wild boar and red deer are usually considered maintenance hosts in Iberian Peninsula and epidemiological evidence has been gathered to support this view (Table 5) based on the 
characterization of populations maintaining high bTB prevalence rates despite long-term lack of contacts with cattle. Fallow deer, Barbary sheep and badger are also discussed as possible maintenance hosts, while all other reported hosts are considered spillover. Wild boar, red and fallow deer have been suggested as possible reservoirs of infection for livestock.

\subsection{Molecular epidemiology}

The most commonly identified causative agent of bTB in Iberian Peninsula has been $M$. bovis, although a small proportion $(0,05, \mathrm{n}=829)$ of Mycobacterium caprae was reported in $6 / 15$ studies. $M$. caprae is much more frequent among isolates from wild boar $(0,08, n=502)$ than from red deer $(0,01, \mathrm{n}=327)$. Mycobacterium avium-complex mycobacteria and other mycobacteria have also been isolated from wild hosts, but they fall out of the scope of the present review. Molecular epidemiology studies rely mostly on spoligotyping (14/15), usually coupled with MIRU-VNTR typing (9/15) (Table 6).

\section{Discussion}

\subsection{Characterization of published articles}

Most epidemiological studies on wild boar or red deer are cross-sectional, allowing for the estimation of prevalence rates and simultaneously the identification of risk or protective factors. A few of the earliest studies were surveys; also classified as such were some molecular epidemiology articles that allow calculating prevalence rates. As knowledge of $\mathrm{bTB}$ on other species is more recent, a larger proportion of these studies are case reports and surveys. A comparatively large number of studies address molecular epidemiology.

Notably absent from the literature are case-control studies, which could shed light on the importance of specific determinants of disease, such as fencing and provision of feed and water. The same should be mentioned for experimental studies, were exposure to a certain determinant of disease is manipulated and the effect on disease occurrence is then measured. This design could be of great help to ascertain the role of each species in the persistence of $\mathrm{bTB}$, trough manipulation of host density. The same can be said for epidemiological modelling, which could provide a theoretical framework for understanding bTB persistence in Iberian Peninsula and test the effect of different control measures (Thrushfield et al., 1995) and also to identify key data on host populations and wildlife tuberculosis that is missing or that is not feasible or up to date.

Most articles resort to targeted surveillance of hunted or culled animals, which allows prevalence estimation. Culling is expected to be less sex and age-biased than recreational hunting, which focuses on specific age (adults) and sex (males) classes. The hunting method used for harvesting the animals (drive hunts) is less selective than trophy hunting, allowing access also to females and juvenile/subadult animals (Fernández-Llario \& Mateos-Quesada, 2003; Martínez et al., 2005). Hunted animals are usually considered a representative sample of the population for health monitoring, at least for non neurological or debilitating diseases (Conner et al., 2000). Nevertheless it should be kept in mind that some sampling biases can be present (Wilson et al., 2001). 


\begin{tabular}{|c|c|c|c|c|c|c|}
\hline $\begin{array}{l}\text { Taxonomic } \\
\text { Order }\end{array}$ & Species & $\begin{array}{l}\text { Diagnostic } \\
\text { technique }\end{array}$ & $\begin{array}{l}\text { Mycobacterial } \\
\text { species }\end{array}$ & $\begin{array}{c}\text { Meta } \\
\text { prevalence }\end{array}$ & $\begin{array}{c}\text { Epidemiological } \\
\text { status }\end{array}$ & References \\
\hline \multirow[t]{7}{*}{ Artiodactyla } & $\begin{array}{l}\text { Wild boar } \\
\text { Sus scrofa }\end{array}$ & $\begin{array}{l}\text { Bacteriology } \\
\text { culture } \\
\text { other }\end{array}$ & $\begin{array}{l}\text { M. bovis } \\
\text { M. caprae }\end{array}$ & $\begin{array}{c}276 / 771 \\
(35,8 \%)\end{array}$ & $\begin{array}{l}\text { Maintenance } \\
\text { host } \\
\text { Reservoir? }\end{array}$ & $\begin{array}{l}\text { Aranaz et al. (2004) } \\
\text { Acevedo-Whitehouse } \\
\text { et al. }(2005) \\
\text { Gortázar et al. (2008) } \\
\text { Romero et al. (2008) } \\
\text { Santos et al. (2009) } \\
\text { Pinto et al. (2011) } \\
\text { others }\end{array}$ \\
\hline & $\begin{array}{l}\text { Red deer } \\
\text { Cervus elaphus }\end{array}$ & $\begin{array}{l}\text { Bacteriology } \\
\text { culture } \\
\text { other }\end{array}$ & $\begin{array}{l}\text { M. bovis } \\
\text { M. caprae }\end{array}$ & $\begin{array}{l}78 / 371 \\
(21,0 \%)\end{array}$ & $\begin{array}{l}\text { Maintenance } \\
\text { host } \\
\text { Reservoir? }\end{array}$ & $\begin{array}{l}\text { Aranaz et al. (2004) } \\
\text { Gortázar et al. (2008) } \\
\text { Romero et al. (2008) } \\
\text { Pinto } \text { et al. (2011) } \\
\text { others }\end{array}$ \\
\hline & $\begin{array}{l}\text { Fallow deer } \\
\text { Dama dama }\end{array}$ & $\begin{array}{l}\text { Bacteriology } \\
\text { culture } \\
\text { other }\end{array}$ & M. bovis & $\begin{array}{l}116 / 420 \\
(27,6 \%)\end{array}$ & $\begin{array}{l}\text { Maintenance } \\
\text { host? } \\
\text { Spillover host? } \\
\text { Reservoir host? }\end{array}$ & $\begin{array}{l}\text { Aranaz et al. (2004) } \\
\text { Gortázar et al. (2008, } \\
\text { 2011) } \\
\text { Romero et al. (2008) } \\
\text { others }\end{array}$ \\
\hline & $\begin{array}{l}\text { Chamois } \\
\text { Rupicapra } \\
\text { pyrenaica }\end{array}$ & $\begin{array}{l}\text { Bacteriology } \\
\text { culture }\end{array}$ & M. bovis & & Spillover host & $\begin{array}{l}\text { Rodríguez et al. } \\
(2010)\end{array}$ \\
\hline & $\begin{array}{l}\text { Mouflon } \\
\text { Ovis orientalis }\end{array}$ & $\begin{array}{l}\text { Bacteriology } \\
\text { culture }\end{array}$ & M. bovis & & Spillover host & $\begin{array}{l}\text { Rodríguez et al. } \\
(2010)\end{array}$ \\
\hline & $\begin{array}{l}\text { Barbary sheep } \\
\text { Ammotragus } \\
\text { lervia }\end{array}$ & $\begin{array}{l}\text { Bacteriology } \\
\text { culture } \\
\text { other }\end{array}$ & M. bovis & & $\begin{array}{l}\text { Spillover host? } \\
\text { Maintenance } \\
\text { host? }\end{array}$ & $\begin{array}{l}\text { Candela et al. (2009) } \\
\text { Rodríguez et al. } \\
(2010)\end{array}$ \\
\hline & $\begin{array}{l}\text { Roe deer } \\
\text { Capreolus } \\
\text { capreolus } \\
\end{array}$ & $\begin{array}{l}\text { IHC } \\
\text { PCR }\end{array}$ & M. bovis & & Spillover host & Balseiro et al. (2009) \\
\hline \multirow[t]{3}{*}{ Carnivora } & $\begin{array}{l}\text { Iberian lynx } \\
\text { Lynx pardina }\end{array}$ & $\begin{array}{l}\text { Bacteriology } \\
\text { culture } \\
\text { other }\end{array}$ & M. bovis & $9 / 40$ & Spillover host & $\begin{array}{l}\text { Briones et al. }(2000) \\
\text { Pérez et al. }(2001) \\
\text { Aranaz et al. }(2004) \\
\text { Atance } \text { et al. }(2006) \\
\text { Romero et al. }(2008) \\
\text { Millán et al. }(2009) \\
\text { Rodríguez et al. } \\
(2010)\end{array}$ \\
\hline & $\begin{array}{l}\text { Red fox } \\
\text { Vulpes vulpes }\end{array}$ & $\begin{array}{l}\text { Bacteriology } \\
\text { culture } \\
\text { other }\end{array}$ & $\begin{array}{l}\text { M. bovis } \\
\text { M. caprae }\end{array}$ & $5 / 45$ & Spillover host & $\begin{array}{l}\text { Atance et al. (2005, } \\
2006) \\
\text { Millán et al. }(2008, \\
2009) \text { Romero } \text { et al. } \\
(2008) \\
\text { Rodríguez et al. } \\
(2010)\end{array}$ \\
\hline & $\begin{array}{l}\text { Badger } \\
\text { Meles meles }\end{array}$ & $\begin{array}{l}\text { Bacteriology } \\
\text { culture } \\
\text { other }\end{array}$ & M. bovis & $8 / 121$ & $\begin{array}{l}\text { Maintenance } \\
\text { host }\end{array}$ & $\begin{array}{l}\text { Atance et al. (2006) } \\
\text { Sobrino et al. (2008) } \\
\text { Rodríguez et al. } \\
(2010) \\
\text { Balseiro et al. }(2011) \\
\end{array}$ \\
\hline
\end{tabular}

Table 5. Bovine tuberculosis host species described in the Iberian Peninsula. For references and meta prevalence rate calculations for wild boar, red and fallow deer only targeteddesign studies using bacteriological culture as diagnostic test on all animals samples are used. Meta prevalence in carnivores is exclusively based on passive-design studies. 


\begin{tabular}{|c|c|c|c|c|c|c|}
\hline Reference & $\begin{array}{c}\text { Sample } \\
\mathrm{n} \\
\text { (Isolates) }\end{array}$ & Technique & Time frame & $\begin{array}{c}\text { Genotypes } \\
n\end{array}$ & Host clustering & Study areas \\
\hline $\begin{array}{l}\text { Aranaz et } \\
\text { al. (1996) }\end{array}$ & $\begin{array}{l}4 \text { wild boar } \\
2 \text { red deer } \\
(129 \text { cattle, } 44 \\
\text { goat, } 1 \text { sheep, } \\
2 \text { cat })\end{array}$ & SP & & $\begin{array}{l}24 \\
\text { spoligotypes } \\
(2 \text { clusters })\end{array}$ & $\begin{array}{l}\text { Sheep/goat isolates clustered apart } \\
\text { from other species }\end{array}$ & \\
\hline $\begin{array}{l}\text { Parra et al. } \\
(2003)\end{array}$ & $\begin{array}{l}37 \text { wild boar } \\
(25 \text { Iberian } \\
\text { pig) }\end{array}$ & $\begin{array}{l}\text { SP } \\
\text { MV }\end{array}$ & $1998-2001$ & \begin{tabular}{|l|}
8 \\
spoligotypes \\
43 combined \\
(14 clusters, \\
21 unique \\
profiles $)$ \\
\end{tabular} & \begin{tabular}{|l}
4 Iberian pig-only clusters \\
7 wild boar-only clusters \\
2 common clusters (14 genotypes)
\end{tabular} & $\begin{array}{l}1 \text { area W } \\
\text { Spain }\end{array}$ \\
\hline $\begin{array}{l}\text { Aranaz et } \\
\text { al. (2004) }\end{array}$ & \begin{tabular}{|l|}
33 red deer \\
62 fallow \\
deer \\
58 wild boar \\
3 Iberian lynx \\
(50 cattle) \\
\end{tabular} & SP & 1996-2002 & $\begin{array}{l}21 \\
\text { spoligotypes }\end{array}$ & $\begin{array}{l}17 \text { genotypes in wild boar (4 } \\
\text { exclusive) } \\
8 \text { genotypes red deer (none exclusive) } \\
6 \text { fallow deer ( } 1 \text { exclusive) } \\
10 \text { cattle ( } 3 \text { exclusive) }\end{array}$ & $\begin{array}{l}7 \text { areas SW } \\
\text { Spain }\end{array}$ \\
\hline $\begin{array}{l}\text { Gortázar et } \\
\text { al. (2005) }\end{array}$ & $\begin{array}{l}58 \text { wild boar } \\
19 \text { red deer }\end{array}$ & \begin{tabular}{|l} 
SP \\
MV
\end{tabular} & $1999-2002$ & \begin{tabular}{|l|}
11 \\
spoligotypes \\
19 combined \\
\end{tabular} & $\begin{array}{l}10 \text { spoligotypes wild boar ( } 5 \\
\text { exclusive) } \\
6 \text { spoligotypes red deer ( } 1 \text { exclusive) }\end{array}$ & $\begin{array}{l}24 \text { areas SW } \\
\text { Spain }\end{array}$ \\
\hline $\begin{array}{l}\text { Parra et al. } \\
(2005)\end{array}$ & $\begin{array}{l}112 \text { wild boar } \\
59 \text { red deer } \\
(6 \text { cattle, } 28 \\
\text { Iberian pig, } 2 \\
\text { goat) }\end{array}$ & $\begin{array}{l}\text { SP } \\
\text { MV }\end{array}$ & $1998-2003$ & \begin{tabular}{|l|}
14 \\
spoligotypes \\
131 \\
combined \\
(28 clusters, \\
76 unique \\
profiles $)$ \\
\end{tabular} & $\begin{array}{l}22 \text { clusters wild boar ( } 8 \text { exclusive) } \\
13 \text { clusters red deer ( } 3 \text { exclusive) } \\
7 \text { clusters pig ( } 2 \text { exclusive) } \\
3 \text { clusters cattle (1 exclusive) } \\
1 \text { cluster goat }\end{array}$ & $\begin{array}{l}1 \text { area } W \\
\text { Spain }\end{array}$ \\
\hline $\begin{array}{l}\text { de } \\
\text { Mendoza } \\
\text { et al. }(2006)\end{array}$ & $\begin{array}{l}11 \text { wild boar } \\
8 \text { red deer } \\
(5 \text { cattle })\end{array}$ & $\begin{array}{l}\text { SP } \\
\text { MV }\end{array}$ & $1992-2004$ & $\begin{array}{l}(4 \text { clusters, } \\
10 \text { unique } \\
\text { profiles })\end{array}$ & & $\begin{array}{l}1 \text { area W } \\
\text { Spain }\end{array}$ \\
\hline $\begin{array}{l}\text { Duarte } e t \\
\text { al. }(2008)\end{array}$ & $\begin{array}{l}21 \text { red deer } \\
6 \text { wild boar } \\
(258 \text { cattle, } 8 \\
\text { goat })\end{array}$ & $\mathrm{SP}$ & $2002-2007$ & $\begin{array}{l}29 \\
\text { spoligotypes }\end{array}$ & $\begin{array}{l}11 \text { spoligotypes red deer ( } 2 \text { exclusive) } \\
5 \text { spoligotypes wild boar (none } \\
\text { exclusive) } \\
27 \text { spoligotypes cattle ( } 15 \text { exclusive) }\end{array}$ & Portugal \\
\hline $\begin{array}{l}\text { Romero et } \\
\text { al. }(2008)\end{array}$ & $\begin{array}{l}60 \text { wild boar } \\
26 \text { red deer } \\
17 \text { fallow } \\
\text { deer } \\
4 \text { Iberian lynx } \\
2 \text { red fox } \\
(54 \text { cattle) }\end{array}$ & $\begin{array}{l}\text { SP } \\
\text { MV }\end{array}$ & $1998-2003$ & $\begin{array}{l}9 \\
\text { spoligotypes }\end{array}$ & $\begin{array}{l}3 \text { spoligotypes wild boar (none } \\
\text { exclusive) } \\
2 \text { spoligotypes red \& fallow deer \& } \\
\text { red fox (none exclusive) } \\
2 \text { spoligotypes Iberian lynx ( } 1 \\
\text { exclusive) } \\
11 \text { spoligotypes cattle ( } 8 \text { exclusive) }\end{array}$ & $\begin{array}{l}1 \text { area SW } \\
\text { Spain }\end{array}$ \\
\hline $\begin{array}{l}\text { Duarte } \text { et } \\
\text { al. (2009) }\end{array}$ & $\begin{array}{l}13 \text { red deer } \\
4 \text { wild boar } \\
\text { (157 cattle, } 7 \\
\text { goat) }\end{array}$ & MV & $2002-2007$ & $\begin{array}{l}87 \\
\text { genotypes }\end{array}$ & $\begin{array}{l}12 \text { genotypes red deer ( } 8 \text { exclusive) } \\
4 \text { genotypes wild boar ( } 1 \text { exclusive) } \\
78 \text { genotypes cattle ( } 71 \text { exclusive) }\end{array}$ & Portugal \\
\hline \begin{tabular}{|l} 
Santos et al. \\
$(2009)$
\end{tabular} & 14 wild boar & SP & $2005-2006$ & \begin{tabular}{|l|}
4 \\
spoligotypes \\
\end{tabular} & & \begin{tabular}{|l|}
3 areas \\
Portugal \\
\end{tabular} \\
\hline $\begin{array}{l}\text { Rodríguez } \\
\text { et al. (2010) }\end{array}$ & \begin{tabular}{|l|}
204 wild boar \\
141 red deer \\
229 fallow \\
deer \\
2 chamois \\
1 mouflon \\
6 Iberian lynx \\
2 red fox \\
1 badger \\
\end{tabular} & SP & $1992-2007$ & \begin{tabular}{|l|}
252 \\
spoligotypes
\end{tabular} & $\begin{array}{l}26 \text { spoligotypes wild boar (6 } \\
\text { exclusive) } \\
22 \text { spoligotypes red deer ( } 2 \text { exclusive) } \\
13 \text { spoligotypes fallow deer ( } 1 \\
\text { exclusive) } \\
1 \text { spoligotype chamois (none } \\
\text { exclusive) } \\
1 \text { spoligotype mouflon ( } 1 \text { exclusive) } \\
3 \text { spoligotypes lynx (none exclusive) }\end{array}$ & Spain \\
\hline
\end{tabular}




\begin{tabular}{|c|c|c|c|c|c|c|}
\hline & $\begin{array}{l}(5585 \text { cattle, } \\
33 \text { goat, } 7 \text { pig, } \\
3 \text { cat, } \\
1 \text { dog })\end{array}$ & & & & $\begin{array}{l}2 \text { spoligotypes red fox (none } \\
\text { exclusive) } \\
1 \text { spoligotype badger (none exclusive) } \\
239 \text { spoligotypes cattle ( } 207 \text { exclusive) } \\
3 \text { spoligotypes goat ( } 1 \text { exclusive) } \\
2 \text { spoligotypes pig (none exclusive) } \\
3 \text { spoligotypes cat ( } 1 \text { exclusive) } \\
1 \text { spoligotype dog (none exclusive) }\end{array}$ & \\
\hline $\begin{array}{l}\text { Cunha et } \\
\text { al. (2012) }\end{array}$ & $\begin{array}{l}74 \text { red deer } \\
36 \text { wild boar }\end{array}$ & $\begin{array}{l}\text { SP } \\
\text { MV }\end{array}$ & 2008-2009 & $\begin{array}{l}27 \\
\text { spoligotypes }\end{array}$ & $\begin{array}{l}21 \text { spoligotypes red deer (11 } \\
\text { exclusive) } \\
15 \text { spoligotypes wild boar ( } 5 \\
\text { exclusive) } \\
6 \text { spoligotypes exclusive of wildlife } \\
\text { vs } 23 \text { spoligotypes exclusive of } \\
\text { domestic species }\end{array}$ & $\begin{array}{l}4 \text { regions } \\
\text { South- } \\
\text { Central } \\
\text { Portugal }\end{array}$ \\
\hline $\begin{array}{l}\text { Gortázar et } \\
\text { al. (2011) }\end{array}$ & $\begin{array}{l}24 \text { red deer } \\
21 \text { fallow } \\
\text { deer } \\
62 \text { wild boar }\end{array}$ & $\begin{array}{l}\text { SP } \\
\text { MV }\end{array}$ & 2006-2007 & \begin{tabular}{|l|} 
\\
spoligotypes \\
13 \\
genotypes \\
combined \\
\end{tabular} & $\begin{array}{l}8 \text { genotypes red deer ( } 2 \text { exclusive) } \\
6 \text { genotypes fallow deer (none } \\
\text { exclusive) } \\
5 \text { genotypes wild boar (none } \\
\text { exclusive) }\end{array}$ & $\begin{array}{l}1 \text { area SW } \\
\text { Spain }\end{array}$ \\
\hline $\begin{array}{l}\text { Pinto et al. } \\
(2011)\end{array}$ & $\begin{array}{l}27 \text { red deer } \\
21 \text { wild boar }\end{array}$ & $\mathrm{SP}$ & 2008-2009 & \begin{tabular}{|l|}
8 \\
spoligotypes
\end{tabular} & $\begin{array}{l}8 \text { spoligotypes red deer ( } 4 \text { exclusive) } \\
4 \text { spoligotypes wild boar (none } \\
\text { exclusive) }\end{array}$ & $\begin{array}{l}1 \text { area } \\
\text { Central } \\
\text { Portugal } \\
\end{array}$ \\
\hline $\begin{array}{l}\text { Rodriguez } \\
\text { et al. (2011) }\end{array}$ & $\begin{array}{l}14 \text { wild boar } \\
1 \text { red deer } \\
1 \text { red fox } \\
\text { (542 goat, } 229 \\
\text { cattle, } 2 \\
\text { sheep, } 2 \text { pig) }\end{array}$ & $\begin{array}{l}\text { SP } \\
\text { MV }\end{array}$ & 1992-2009 & \begin{tabular}{|l|}
15 \\
spoligotypes
\end{tabular} & $\begin{array}{l}4 \text { spoligotypes wild boar (none } \\
\text { exclusive) } \\
1 \text { spoligotype red (none exclusive) } \\
1 \text { spoligotype red fox (none exclusive) } \\
12 \text { spoligotypes goat ( } 6 \text { exclusive) } \\
9 \text { spoligotypes cattle ( } 2 \text { exclusive) } \\
2 \text { spoligotypes sheep, pig (none) }\end{array}$ & Spain \\
\hline
\end{tabular}

Table 6. Molecular biology studies included in the analysis. SP: spoligotyping, MV: MIRUVNTR mycobacterial interspersed repetitive units-variable number of tandem repeats.

On the other hand, studies of wild ungulates relying on routine meat inspection for detection of macroscopic tuberculosis-like lesions, do not allow for a reliable estimation of prevalence, which is underestimated in this situation (de Mendonza et al., 2006). Nevertheless this type of design allows increasing sample size, which makes them suited for long-term surveillance rather than detailed epidemiological studies (de Mendonza et al., 2006) and were mostly used in the first surveys and cross-sectional studies after bTB was detected in wildlife in Iberian Peninsula. The investigations on carnivore species, most of which are not hunted, tend to rely on passive surveillance schemes based on haphazardly found carcasses. This sampling design does not allow to estimate prevalence rates due to extensive sampling bias (e.g. Taylor et al., 2002). Targeted sampling in these species has been attempted using serological tests but results should be interpreted with caution since these techniques have not yet been validated in these species.

The number of animals studied is usually adequate to determine prevalence rates with relatively small confidence intervals, at least in the easily available hunted species. The same cannot be said for most studies on protected carnivore species, where the collection of biological samples from a large number of animals is inherently difficult.

Bacteriological culture is the reference test for diagnosing bTB although it is expensive and time-consuming (de Lisle et al., 2002). As the financial resources needed to perform bacteriological culture on a large number of samples are scarcely available, most surveys use 
other methods (usually gross pathology) as screening tests and only perform bacteriological culture for lesion-positive animals, sometimes as pooled samples. This introduces a bias and it was shown that the sensitivity of gross pathology was $72,2 \%$ of that obtained from bacteriology in the wild boar (Santos et al., 2010). The same trend has been reported elsewhere for deer (Rohonczy et al., 1996; O’Brien et al., 2004).

\subsection{Prevalence rates}

Overall prevalence rates reported for bTB in wild boar, red deer and fallow deer in Iberian Peninsula are among the highest recorded for these species worldwide (Corner, 2006; Nishi et al.; 2006, Wilson et al., 2008). Interestingly, prevalence rates in wild boar are invariably higher than in sympatric red or fallow deer (Gortázar et al., in press).

Most studies report no sex differences in infection rates, but Santos et al. (2009) reported a significantly higher infection rate in female wild boar, presumably linked to more frequent social behaviour of females compared to males. Several studies report age differences in infection rates in wild boar, but data is conflicting since some authors reported increasing prevalence rates with age (e.g. Vicente et al., 2006a,b), while others found higher prevalence rate in juveniles (e.g. Gortázar et al., 2008; Santos et al., 2009). Age and sex differences in prevalence rates were also reported in red deer (Vicente et al., 2006a), which were higher for males and increased with age. This gender difference was already reported for cervids in North America (O’Brien et al., 2006).

\subsection{Trends}

The few published data about the temporal dynamics of bTB prevalence rates are unanimous in showing an increasing trend across Iberian Peninsula in both wild boar and red deer (de Mendonza et al., 2006; Gortázar et al., 2008, 2011b, in press; Santos et al., 2009, unpublished data). Gortázar et al., (2011b) recently reported that 11/14 wild ungulate populations from central Spain show increasing bTB prevalence rates as assessed by gross pathology. This strongly supports previous interpretations that bTB is an emerging disease in wildlife in Iberian Peninsula.

The highest prevalence rates for bTB reported in wild ungulates in Iberian Peninsula lie in the central-south-western mountain chains of Montes de Toledo-Sierra Morena-Contenda (e.g. Vicente et al., 2006a; Santos et al., 2009) and Doñana (Gortázar et al., 2008). Prevalence rates decline to the periphery of this region; the detected limits of this bTB core area are the provinces of Cáceres/Âvila to the north, eastern Portugal to the West, the Mediterranean coast to the South and Teruel to the East. bTB has not been detected or only sporadically in the northern, western and eastern periphery of Iberian Peninsula, despite locally intense surveillance (Gortázar et al., 2011b). This pattern, coupled with the abovementioned increase in prevalence over time, strongly suggests that the disease is expanding from the central core area.

Interestingly, this core region of high bTB prevalence rates coincides with the main historical refuge of the wild boar in Spain (Tellería \& Saez-Royuela, 1985) and, to some extent, in Portugal (Lopes \& Borges, 2004). In the beginning of the $X X^{\text {th }}$ century, Iberian populations of wild ungulates were at their lowest level due to intense direct persecution and were largely restricted to a few mountain regions. Starting in 1960's, wild boar populations expanded from these refuges (Tellería \& Saez-Royuela, 1985; Acevedo et al., 2011) to a point they 
nowadays occupy almost all Iberian Peninsula (Rosell, 2001). Natural expansion of red deer also occurred but not to such a great extent as in the wild boar case and was much dependent upon translocations (Soriguer, 1998; Acevedo et al., 2011).

As suggested by Santos et al. (2009) for Portugal, wildlife bTB could be similarly expanding from the historical refuges with a lag comparative to its host's expansion. This lag could be explained by the threshold theory for disease persistence, as reported for other bTB hosts such as the possum Trichosurus vulpecula in New Zealand - Lloyd-Smith et al., 2005). As wild ungulate populations expanded, densities at the front of the expansion wave were too low (Holland et al., 2007) to allow for the persistence of bTB, even if presumably some infected hosts were involved in that expansion event. As a consequence, wildlife bTB initially remained confined to the historical refuges, despite dispersion of infected hosts. As ungulate distribution continued to expand, densities increased in a gradient centred at the historical refuges and eventually reached the threshold level. At that point, bTB, introduced by infected immigrants from the historical refuges, could persist and spread its distribution, a process seemingly still taking place.

This hypothesis could be tested by comprehensive geographical spatial analysis of the distribution of bTB in Iberian Peninsula, but the proposed natural expansion pattern has probably been much obscured by translocation and intensive management of ungulates for hunting purposes (Vargas et al. 1995; Miguel et al. 1999; Castillo et al., 2010). In fact, in South-central Spain lack of geographical autocorrelation in prevalence rates was suggested to be due to extensive fencing of intensively-managed big game hunting estates, which impair animal movements (Vicente et al., 2006b). On the other hand, wild ungulate translocations for hunting purposes occur frequently and may spread M. bovis to areas where it is absent today. Interestingly, M. bovis was isolated from wild boar in Portugal in two areas widely out of the known distribution of the disease (Santos et al., 2009; Cunha et al., 2012), one of which coincides with the release site of red deer originating from a population harbouring the same genotype of M. bovis. This provides circumstantial evidence for the role of translocations on bTB geographical spread.

More spatial data of bTb occurrence in Iberian Peninsula is urgently needed. The advent of sensitive, specific, reproducible and cheap serologic tests allows such large-scale research to be conducted, at least for wild boar (Boadella et al., 2011). This should improve the understanding of bTB occurrence across Iberian Peninsula.

\subsection{Disease determinant factors}

Most risk factors for bTB in wild boar and red deer identified in Iberian Peninsula are host population factors, most of them abundance-related. It is interesting to note that in the wild boar-red deer system, the abundance of each species influences bTB occurrence in the other species, further supporting the multi-host pathogen status of bTB in Iberian Peninsula ecosystems.

The number of risk factors related to management is greater for the red deer $(n=5)$ than for the wild boar $(n=1)$. This suggests that bTB occurrence in red deer populations is more dependent on management practices, while wild boar is competent to act as maintenance host under low-intensity management. This hypothesis could be tested by a case-control study of bTB occurrence in both species across a gradient of intensity of management. 
Interestingly, among the protective risk factors described for bTB in Doñana, distance to freshwater sources is highlighted. Much remains to be known on the conditions necessary for the survival of mycobacteria in the environment, but humidity seems to favour it (Humblet et al., 2009), particularly in the arid summer conditions of southern Iberian Peninsula. This suggests that environmental contamination with mycobacteria, particularly at watering sites, and indirect routes could play a role in disease transmission among wild ungulate species.

\subsection{Host status}

Wild boar and red deer are usually referred as maintenance hosts in Iberian Peninsula and evidence is available as populations maintaining high prevalence rates for several years, even decades, in the absence of domestic cattle which could theoretically serve as reservoirs for wildlife (e.g. Vicente et al., 2006a; Gortázar et al., 2008). It seems consensual that high-density sympatric populations of wild boar and red deer can maintain bTB at a high prevalence independent of the existence of other hosts (e.g. de Mendonza et al., 2006; Vicente et al., 2006a; Gortázar et al., in press). This seems also to be independent of intensity of management for hunting purposes, favouring high density of animals through habitat management, feeding and watering (Miguel et al., 1999), as even non-intensively managed but high-density populations of wild boar show high bTB prevalence rates (Santos et al., 2009).

It should be noted that in most of Iberian Peninsula densities far above the natural carrying capacity of wild boar and red deer occur, even in the absence of intensive management, because natural predators of these species (essentially wolf Canis lupus) have been eliminated during the last 50 years (Rico \& Torrente, 2000). Packer et al. (2003) have shown through modelling that removal of predators can lead to an increase on pathogens' prevalence. Furthermore, Barber-Meyer et al. (2007) have shown that wolf restoration in Yellowstone had significant impacts on the seroprevalence of several pathogens of deer, even though those populations were previously subject to predation by other species.

It could be hypothesized that the current bTB high prevalence rates in wildlife in Iberian Peninsula derives from severe changes on the ecosystems caused by intensive management for hunting purposes (Gortázar et al., 2006) and eventually also predator eradication (Rico \& Torrente, 2000). Experimental studies where host density is manipulated through large-scale culling are absent from the literature and could help to understand the role of artificialization of the ecosystems in the persistence and expansion of bTB. The picture is further complicated by the difficulty in separating the effect of each host species, as they usually occur in sympatry in the core area. Nevertheless, wild boar populations have been reported to show high bTB prevalence rates even in the absence of sympatric deer (Vicente et al., 2006a).

Fallow deer and badger are most likely local maintenance hosts where they occur at high density, notably in scattered populations of fallow deer and in Atlantic Iberian Peninsula for the badger. On the other hand, other carnivore and ungulate species infected in Iberian Peninsula are most likely spillover hosts, with the possible exception of exotic Barbary sheep.

\subsection{Molecular epidemiology}

Studies reviewed are rather concordant in concluding that genotypes seem to be geographically clustered as each location has a few predominant genotypes, responsible for 
the majority of the infections. Concurrently, there is also a wide variety of locally rare genotypes. Local genotypes tend to be the same in different sympatric species, both domestic and wild, supporting the local interspecies transmission of $M$. bovis.

\section{Conclusion}

In summary, published evidence suggests that bTB is a natural pathogen of autochthonous wild ungulates in Iberian Peninsula, where wild boar and red deer act as maintenance hosts. Bovine tuberculosis is an emergent disease in these hosts, the expansion from the core high prevalence area in south-western Iberian Peninsula being fuelled by high densities of these species due to intensive management for hunting purposes. Several other species of ungulates and carnivores are affected by bTB, most probably as spillover hosts, but fallow deer and badger could serve as maintenance host in some locations. Although shown to be an important emerging infection, large gaps remain in the knowledge of the epidemiology of bTB in wildlife, such as intra and inter-species transmission routes, geographical distribution and effectiveness of control methods. Applying different epidemiological study designs, such as case-control and experimental studies, spatial analysis and modelling could shed light on this subject.

\section{References}

Acevedo, P., Farfán, M., Márquez, A., Delibes-Mateos, M., Real, R. \& Vargas, J. (2011) Past, present and future of wild ungulates in relation to changes in land use. Landscape Ecology, 26:19-31, ISSN 0921-2973

Acevedo-Whitehouse, K., Vicente, J., Gortázar, C., Höfle, U., Fernández-de-Mera, I. \& Amos, W. (2005) Genetic resistance to bovine tuberculosis in the Iberian wild boar. Molecular Ecology, 14: 3209-3217, ISSN 0962-1083

Allepuz, A., Casals, J., Nappa, S., Saez, M., Alba, A., Vilar, M., Domingo, M., González, M., DuranFerrer, M., Vicente, J., Álvarez, J., Muñoz, M. \& Saez, J. (2011) Analysis of the spatial variation of bovine tuberculosis disease risk in Spain (2006-2009). Preventive Veterinary Medicine, 100(1): 44-52, ISSN 0167-5877

Aranaz, A., Liébana, E., Mateos, A., Domínguez, L., Vidal, D., Domingo, M., González, O., Rodriguez-Ferri, E., bunschoten, A., van Embden, J. \& Cousins, D. (1996) Spacer oligonucleotide typing of Mycobacterium bovis strains from cattle and other animals: a tool for studying epidemiology of tuberculosis. Journal of Clinical Microbiology, 34(11): 2734-2740

Aranaz, A., de Juan, L., Montero, N., Sánchez, C., Galka, M., Delso, C., Álvarez, J., Romero, B., Bezos, J., Vela, A., Briones, V., Mateos, A. \& Domínguez, L. (2004) Bovine tuberculosis (Mycobacterium bovis) in wildlife in Spain. Journal of Clinical Microbiology, 42(6): 2602-2608

Artois, M., Delahay, R., Guberti, V. \& Cheeseman, C. (2001) Control of infectious diseases of wildlife in Europe. Veterinary Journal, 162: 141-152, ISSN 1090-0233

Atance, P., Palomares, F., Candela, M., Revilla, E., Cubero, M., Calzada, J. \& Vizcaíno, L. (2005) Bovine tuberculosis in a free ranging red fox (Vulpes vulpes) from Doñana National Park (Spain). Journal of Wildlife Diseases, 41(2): 435-436, ISSN 0090-3558

Atance, P., Vizcaíno, L., Palomares, F., Revilla, E., Candela, M., Calzada, Cubero-Pablo, J. \& Delibes, M. (2006) Antibodies to Mycobacterium bovis in Wild Carnivores from 
Doñana National Park (Spain). Journal of Wildlife Diseases, 42(3): 704-708, ISSN 00903558

Balseiro, A., Oleaga, A., Orusa, R., Robetto, S., Domenis, L., Zoppi, S., Dondo, A., Goria, M., Gortázar, C. \& Marín, J. (2009) Tuberculosis in roe deer from Spain and Italy. Veterinary Record, 164: 468-470, ISSN 0042-4900

Balseiro, A., Rodríguez, O., González-Quirós, P., Merediz, I., Sevilla, I., Davé, D., Dalley, D., Lesellier, D., Chambers, M., Bezos, J., Muñoz, M., Delahay, R., Gortázar, C. \& Prieto, J. (2011) Infection of Eurasian badgers (Meles meles) with Mycobacterium bovis and Mycobacterium avium complex in Spain. Veterinary Journal, 190(2): 21-25, ISSN 1090-0233

Barber-Meyer, S., Whit, P. \& Mech, L. (2007) Survey of Selected Pathogens and Blood Parameters of Northern Yellowstone Elk: Wolf Sanitation Effect Implications. American Midland Naturalist, 158: 369-381, ISSN 0003-0031

Boadella, M., Lyashchenko, K., Greenwald, R., Esfandiari, J., Jaroso, R., Carta, T., Garrido, J., Vicente, J., de la Fuente, J. \& Gortázar, C. (2011) Serologic tests for detecting antibodies against Mycobacterium bovis and Mycobacterium avium subspecies paratuberculosis in Eurasian wild boar (Sus scrofa scrofa). Journal Veterinary Diagnostic Investigations, 23: 77-83, ISSN 1040-6387

Boadella, M., Acevedo, P., Vicente, J., Mentaberre, G., Balseiro, A., Arnal, M., Martínez, D., García-Bocanegra, I., Casal, C., Álvarez, J., Oleaga, A., Lavín, S., Muñoz, M., SáezLlorente, J., de la Fuente, J. \& Gortázar, C. (2011) Spatio-temporal trends of Iberian wild boar contact with Mycobacterium tuberculosis complex detected by ELISA. EcoHealth, doi: 10.1007/s10393-011-0713-y, ISSN 1612-9210

Briones, V., de Juan, L., Sánchez, C., Vela, A., Galka, M., Montero, N., Goyache, J., Aranaz, A., Mateos, A. \& Domínguez, L. (2000) Bovine tuberculosis and the endangered Iberian Lynx. Emerging Infectious Diseases, 6(2): 189-191, ISSN 1080-6040

Candela, M., Serrano, E., Martinez-Carrasco, C., Martín-Atance, C., Cubero, M., Alonso, F. \& Leon, L. (2009) Coinfection is an important factor in epidemiological studies: the first serosurvey of the aoudad (Ammotragus lervia). European Journal of Clinical Microbiology Infectious Diseases, 28:481-489, ISSN 0934-9723

Castillo, L., Fernández-Llario, p., Mateos, C., Carranza, J., Benítez-Medina, J., García-Jiménez, W., Bermejo-Martín, F. \& de Mendoza, J. (2010) Management practices and their association with Mycobacterium tuberculosis complex prevalence in red deer populations in Southwestern Spain. Preventive Veterinary Medicine, 98(1): 58-63, ISSN 0167-5877

Clifton-Hadley, R., Sauter-Louis, C., Lugton, I., Jackson, R., Durr, P. \& Wilesmith, J. (2001) Mycobacterium bovis infections, In: Infectious diseases of wild mammals. E. Williams \& I. Barker, pp. 340-361, 3rd edition, Manson Publishing/The Veterinary Press, ISBN 9781840760057, London

Conner, M., McCarty, C. \& Miller, M. (2000) Detection of bias in harvest-based estimates of Chronic Wasting Disease prevalence in Mule deer. Journal of Wildlife Diseases, 36(4): 691-699, ISSN 0090-3558

Corner, L. (2006) The role of wild animal populations in the epidemiology of tuberculosis in domestic animals: how to assess the risk. Veterinary Microbiology, 112: 303-312, ISSN 0378-1135

Cunha, M., Monteiro, M., Carvalho, P., Mendonça, P., Albuquerque, T. \& Botelho, A. (2011) Multihost tuberculosis: insights from the Portuguese control program. Veterinary Medicine International, 2011: doi:10.4061/2011/795165, ISSN 2042-0048 
Cunha, M., Matos, F., Canto, A., Albuquerque, T., Alberto, J., Aranha, J., Pinto, M. \& Botelho, A. (2012) Implications and challenges of tuberculosis in wildlife ungulates in Portugal: A molecular epidemiology perspective. Research in Veterinary Science, 92(2): 225-235, ISSN 0034-5288

Etter, E., Donado, P., Jori, F., Caron, A., Goutard, F. \& Roger, F. (2006) Risk analysis and bovine tuberculosis, a re-emerging zoonosis, Annals New York Academy Sciences, 1081:61-73, ISSN 0077-8923

Fernández-Llario, P. \& Mateos-Quesada, P. (2003) Population structure of the wild boar (Sus scrofa) in two Mediterranean habitats in the western Iberian Peninsula. Folia Zoologica, 52(2): 143-148, ISSN 1573-1189

Gordejo, F. \& Vermeersch, J. (2006) Towards eradication of bovine tuberculosis in the European Union. Veterinary Microbiology, 112: 101-109, ISSN 0378-1135

Gortázar, C., Acevedo, P., Ruiz-Fons, F. \& Vicente, J. (2006) Disease risks and overabundance of game species. European Journal Wildlife Research, 52: 81-87, ISSN 1439-0574

Gortázar, C., Torres, M., Vicente, J., Acevedo, P., Reglero, M., de la Fuente, J., Negro, J. \& Aznar-Martín, J. (2008) Bovine tuberculosis in Doñana Biosphere Reserve: the role of wild ungulates as disease reservoirs in the last Iberian Lynx strongholds. PLoS ONE, 3(7): e2776. doi:10.1371/journal.pone.0002776, ISSN 1932-6203

Gortázar, C., Torres, M., Acevedo, P., Aznar, J., Negro, J., de la Fuente, J. \& Vicente, J. (2011a) Fine-tuning the space, time, and host distribution of mycobacteria in wildlife. BMC Microbiology, 2011, 11:27, ISSN 1471-2180

Gortázar, C., Vicente, J., Boadella, M., Ballesteros, C., Galindo, R., Garrido, J., Aranaz, A. \& de la Fuente, J. (2011b) Progress in the control of bovine tuberculosis in Spanish wildlife. Veterinary Microbiology, 151(1-2): 170-178, ISSN 0378-1135

Gortázar, C., Delahay, R., McDonal, R., Boadella, M., Gavier-Widen, D., Acevedo, P. (in press) The status of tuberculosis in European wild mammals. Mammal Review, ISSN 1365-2907

Holland, E., Aegerter, J. \& Smith, G. (2007) Spatial sensitivity of a generic population model, using wild boar (Sus scrofa) as a test case. Ecological Modelling, 205: 146-158, ISSN 0304-3800

Horan, R., Wolf, C., Fenichel, E. \& Mathews, K. (2008) Joint management of wildlife and livestock disease. Environmental \& Resources Economics, 41:47-70 doi: $10.1007 /$ s10640-007-9180-x, ISSN 1573-1502

Humblet, M., Boschiroli, M. \& Saegerman, C. (2009) Classification of worldwide bovine tuberculosis risk factors in cattle: a stratified approach. Veterinary Research, 40:50 doi: 10.1051/vetres/20090 , ISSN 0928-4249

de Lisle, G., Bengis, R., Schmitt, S. \& O’Brien, D. (2002) Tuberculosis in free-ranging wildlife: detection, diagnosis and management. Revue Scientific et Technique Office International des Epizooties, 21: 317-334, ISSN 0253-1933

Lloyd-smith, J., Cross, P., Briggs, C., Daugherty, M., Getz, W., Latto, J., Sanchez, M., Smith, A. \& Swei, A. (2005) Should we expect population thresholds for wildlife disease? Trends in Ecology and Evolution, 20: 511-520, ISSN 0169-5347

Lopes, F. \& Borges, J. (2004) Wild boar in Portugal. Galemys, 16: 243-251, ISSN 1137-8700

Lyashchenko, K., Greenwald, R., Esfandiari, J., Chambers, A., Vicente, J., Gortazar, C., Santos, N., Correia-Neves, M., Buddle, B., Jackson, R., O’Brien, D., Schmitt, S., Palmer, M., Delahay, R. \& Waters, R. (2008) Animal-side serologic assay for rapid 
detection of Mycobacterium bovis infection in multiple species of free-ranging wildlife. Veterinary Microbiology, 132: 283-292, ISSN 0378-1135

Martínez, M., Rodríguez-Vigal, C., Jones, O., Coulson, T. \& San Miguel, A. (2005) Different hunting strategies select for different weights in red deer. Biology Letters, 1: 353-356, ISSN 1744-9561

Matos, F., Cunha, M., Canto, A., Albuquerque, T., Amado, A. \& Botelho, A. (2010) Snapshot of Mycobacterium bovis and Mycobacterium caprae infections in livestock in a bovine tuberculosis low incidence scenario. Journal of Clinical Microbiology, 48: 4337-4339, ISSN 0095-1137

de Mendoza, J., Parra, A., Tato, A., Alonso, J., Rey, J., Peña, J., García-Sánchez, A., Larrasa, J., Teixidó, J., Manzano, G., Cerrato, R., Pereira, G., Fernández-Llario, P. \& de Mendoza, M. (2006) Bovine tuberculosis in wild boar (Sus scrofa), red deer (Cervus elaphus) and cattle (Bos taurus) in a Mediterranean ecosystem (1992-2004). Preventive Veterinary Medicine, 74: 239-247, ISSN 0167-5877

Miguel, A., Pérez-Carral, C. \& Roig, S. (1999) Deer and traditional agrosilvopastoral systems of Mediterranean Spain. A new problem of sustainability for a new concept of land use. Options Méditerranéennes, 39: 261-264, ISSN 1016-1228.

Millán, J., Jiménez, M., Viota, M., Candela, M., Peña, L. \& Vizcaíno, L. (2008) Disseminated bovine tuberculosis in a wild red fox (Vulpes vulpes) in Southern Spain. Journal of Wildlife Diseases, 44(3): 701-706, ISSN 0090-3558

Millán, J., Candela, M., Palomares, F., Cubero, M., Rodríguez, A., Barral, M., de la Fuente, J., Almería, S. \& Vizcaíno, L. (2009) Disease threats to the endangered Iberian lynx (Lynx pardinus). Veterinary Journal, 182: 114-124, ISSN 1090-0233

Nishi, J., Shury, T. \&, Elkin, B. (2006) Wildlife reservoirs for bovine tuberculosis (Mycobacterium bovis) in Canada: strategies for management and research. Veterinary Microbiology, 112: 325-338, ISSN 0378-1135

O’Brien, D., Schmitt, S., Berry, D., Fitzgerald, S., Vanneste, J., Lyon, T., Magsig, D., Fierke, J., Cooley, T., Zwick, L. \& Thomsen, B. (2004) Estimating the true prevalence of Mycobacterium bovis in hunter-harvested white-tailed deer in Michigan. Journal of Wildlife Diseases, 40(1): 42-52, ISSN 0090-3558

O'Brien, D., Fitzgerald, S., Berry, D. \& Hickling, G. (2006) Managing the wildlife reservoir of Mycobacterium bovis: the Michigan, USA, experience. Veterinary Microbiology, 112: 313- 323, ISSN 0378-1135

Packer, C., Holt, R., Hudson, P., Lafferty, K. \& Dobson, A. (2003) Keeping the herds healthy and alert: implications of predator control for infectious disease. Ecology Letters, 6: 797-802, ISSN 1461-023X

Parra, A., Larrasa, J., García, A., Alonso, J. \& de Mendoza, J. (2005) Molecular epidemiology of bovine tuberculosis in wild animals in Spain: A first approach to risk factor analysis. Veterinary Microbiology, 110 (3-4): 293-300, ISSN 0378-1135

Parra, A., Inglis, N., Tato, A., Alonso, J., de Mendoza, M., de Mendoza, J. \& Larrasa, J. (2006) An epidemiological evaluation of Mycobacterium bovis infections in wild game animals of the Spanish Mediterranean ecosystem. Research in Veterinary Science, 80: 140-146, ISSN 0034-5288

Pérez, J., Calzada, J., Vizcaíno, L., Cubero, M., Velarde, J. \& Mozos, E. (2001) Tuberculosis in an Iberian lynx (Lynx pardina). Veterinary Record, 148: 414-415, ISSN 0042-4900 
Pinto, M., Alberto, J., Aranha, J., Serejo, J., Canto, A., Cunha, M. \& Botelho, A. (2011) Combined evaluation of bovine tuberculosis in wild boar (Sus scrofa) and red deer (Cerous elaphus) from Central-East Portugal. European Journal of Wildlife Research, doi 10.1007/s10344-011-0532-z, ISSN 1612-4642

Renwick, A., White, P. \& Bengis, R. (2007) Bovine tuberculosis in southern African wildlife : a multi-species host-pathogen system. Epidemiology and Infection, 135: 529-540, ISSN 0950-2688

Rico, M. \& Torrente, J. (2000) Caza y rarificación del lobo en españa: investigación histórica y conclusiones biológicas. Galemys, 12:163-179, ISSN 1137-8700

Rodríguez, S., Romero, B., Bezos, J., de Juan, L., Álvarez, J., Castellanos, E., Moya, N., Lozano, F., González, S., Sáez-Llorente, J., Mateos, A., Domínguez, L., Aranaz, A. (2010) High spoligotype diversity within a Mycobacterium bovis population: clues to understanding the demography of the pathogen in Europe. Veterinary Microbiology, 141: 89-95, ISSN 0378-1135

Rodríguez, S., Bezos, J., Romero, B., de Juan, L., Álvarez, J., Castellanos, E., Moya, N., Lozano, F., Javed, M., Sáez-Llorente, J., Liébana, E., Mateos, A., Domínguez, L., Aranaz, A. (2011) Mycobacterium caprae infection in livestock and wildlife, Spain. Emerging Infectious Diseases, 17(3): 532-535, ISSN 1080-6059

Rohonczy, E., Balachandran, A., Dukes, T., Payeur, J., Rhyan, J., Saari, D., Whiting, T., Wilson, S. \& Jarnagin, J. (1996) A comparison of gross pathology, histopathology, and mycobacterial culture for the diagnosis of tuberculosis in elk (Cerous elaphus). Canadian Journal of Veterinary Research, 60: 108-114, ISSN 0830-9000

Romero, B., Aranaz, A., Sandoval, A., Álvarez, J., de Juan, L., Bezos, J., Sánchez, C., Galka, M., Fernández, P., Mateos, A. \& Domínguez, L. (2008) Persistence and molecular evolution of Mycobacterium bovis population from cattle and wildlife in Doñana National Park revealed by genotype variation. Veterinary Microbiology, 132: 87-95, ISSN 0378-1135

Rosell, C., Fernández-Llario, P. \& Herrero, J. (2001) El jabalí (Sus scrofa Linnaeus, 1758). Galemys, 13(2): 1-25, ISSN 1137-8700

Santos, N., Correia-Neves, M., Ghebremichael, S., Källenius, G., Svenson, S. \& Almeida, V. (2009) Epidemiology of Mycobacterium bovis infection in wild boar Sus scrofa from Portugal. Journal of Wildlife Diseases, 45(4): 1048-1061, ISSN 0090-3558

Santos, N., Geraldes, M., Afonso, A., Almeida, V. \& Correia-Neves, M. (2010) Diagnosis of tuberculosis in the wild boar (Sus scrofa): a comparison of methods applicable to hunter-harvested animals. PLoS-ONE, 5(9): e12663, ISSN 1932-6203

Schiller, I., Oesch, B., Vordermeier, M., Palmer, M., Harris, B., Orloski, K., Buddle, B., Thacker, T., Lyashchenko, K. \& Waters, W. (2010) Bovine tuberculosis: a review of current and emerging diagnostic techniques in view of their relevance for disease control and eradication. Transboundary and Emerging Diseases doi:10.1111/j.18651682.2010.01148.x, ISSN 1865-1674

Sobrino, R., Martín-Hernando, M., Vicente, J., Aurtenetxe, O., Garrido, J. \& Gortázar, C. (2008) Bovine tuberculosis in a badger (Meles meles) from Spain. Veterinary Record, 163(5): 159-160, ISSN 0042-4900

Soriguer, R., Márquez, F. \& Pérez, J. (1998) Las translocaciones (introducciones y reintroducciones) de espécies cinegéticas y sus effectos medioambientales. Galemys, 10(2): 19-35, ISSN 1137-8700 
Steele, J. (1995) Regional and Country Status Report, In: Mycobacterium bovis infection in animals and humans, Thoen, C.O. \& J.H. Steele, pp. 169-172, Iowa Press, ISBN 9780470344538, Ames

Swinton, J., Woolhouse, M., Begon, M., Dobson, A., Ferroglio, E., Grenfell, B., Guberti, V., Hails, R., Heesterbeek, J., Lavazza, A., Roberts, M., White, P. \& Wilson, K. (2001) Microparasite transmission and persistence, In: The Ecology of Wildlife Diseases, P. Hudson, A. Rizzoli, B. Grenfell, H. Heesterbeek, A. Dobson, pp. 83-101, Oxford University Press, ISBN 0198506198, Oxford

Taylor, S., Buergelt, C., Roelke-Parker, M., Homer, B. \& Rotstein, D. (2002) Causes of mortality of free-ranging Florida panthers. Journal of Wildlife Diseases, 38(1): 107-114, ISSN 0090-3558

Tellería, J. \& Saez-Royuela, Y. (1985) L'évolution démographique du sanglier (Sus scrofa) en Espagne. Mammalia 49: 195-202, ISSN 0025-1461

Thrushfield, M. (1995) Veterinary epidemiology. $2^{\text {nd }}$ edition, Blackwell Science, ISBN 0632048514, Oxford

Tompkins, D., Dobson, A., Arneberg, P., Begon, M., Cattadori, I., Greenman, J., Heesterbeek, J., Hudson, P., Newborn, D., Pugliese, A., Rizzoli, A., Rosa, R., Rosso, F. \& Wilson, K. (2001) Parasites and host population dynamics, In: The Ecology of Wildlife Disease, P. Hudson, A. Rizzoli, B. Grenfell, H. Heesterbeek, A. Dobson, pp. 45-62, Oxford University Press, ISBN 0198506198, Oxford

Vargas, J. Calvo, J. \& Aparicio, M, (1995) Red deer (Cervus elaphus hispanicus) management in the dehesa system in Central Extremadura, Spain. Agroforestry Systems, 29: 77-89, ISSN 0167-4366.

Vicente, J., Höfle, U., Garrido, J., Fernández-de-Mera, I., Juste, R., Barral, M. \& Gortazar, C. (2006a) Wild boar and red deer display high prevalences of tuberculosis-like lesions in Spain. Veterinary Research, 37: 107-119, ISSN 0928-4249

Vicente, J., Höfle, U., Garrido, J., Fernández-de-Mera, I., acevedo, P., Juste, R., Barral, M. \& Gortazar, C. (2006b) Risk factors associated with the prevalence of tuberculosis-like lesions in fenced wild boar and red deer in south central Spain. Veterinary Research, 38: 1-15, ISSN 0928-4249

Whiting, T. (2003) Foreign animal disease outbreaks, the animal welfare implications for Canada: risks apparent from international experience. Canadian Veterinary Journal: 44: 805-815, ISSN 0008-5286

Wilkins, M., Meyerson, J., Bartlett, P., Spieldenner, S., Berry, D., Mosher, L., Kaneene, J., Robinson-Dunn, B., Stobierski, M. \& Boulton, M. (2008) Human Mycobacterium bovis infection and bovine tuberculosis outbreak, Michigan, 1994-2007. Emerging Infectious Diseases, 14(4):657-660, ISSN 1080-6040

Wilson, K., Bjornstad, O., Dobson, A., Merler, S., Poglayen, G., Randolph, S., Read, A. \& Skorping, A. (2001) Heterogenities in macroparasite infections: patterns and processes, In The Ecology of Wildlife Diseases, P. Hudson, A. Rizzoli, B. Grenfell, H. Heesterbeek, A. Dobson, pp. 6-44, Oxford University Press, ISBN 0198506198, Oxford

Wilson, G., Broughan, J., Chambers, M., Clifton-Hadley, R., Crawshaw, T., de la Fuente, J., Delahay, R., Gavier-Widen, D., Gortazar, C., Hewinson, G., Jackson, V., MartínHernando, M., Neimanis, A., Salguero, F., Vicente, J., Ward, A. \& McDonald, R. (2008) Scientific review on Tuberculosis in wildlife in the European Union. Technical Report submitted to EFSA, 117 pp. 


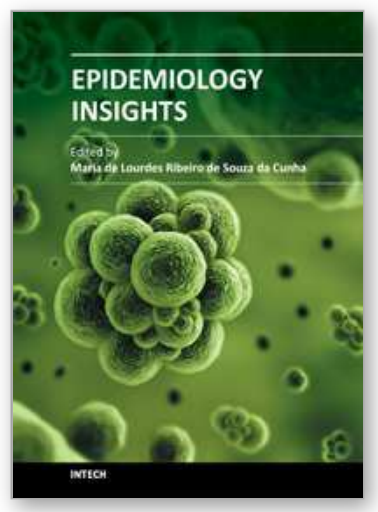

\author{
Epidemiology Insights \\ Edited by Dr. Maria De Lourdes Ribeiro De Souza Da Cunha
}

ISBN 978-953-51-0565-7

Hard cover, 396 pages

Publisher InTech

Published online 20, April, 2012

Published in print edition April, 2012

This book represents an overview on the diverse threads of epidemiological research, brings together the expertise and enthusiasm of an international panel of leading researchers to provide a state-of-the art overview of the field. Topics include the epidemiology of dermatomycoses and Candida spp. infections, the epidemiology molecular of methicillin-resistant Staphylococcus aureus (MRSA) isolated from humans and animals, the epidemiology of varied manifestations neuro-psychiatric, virology and epidemiology, epidemiology of wildlife tuberculosis, epidemiologic approaches to the study of microbial quality of milk and milk products, Cox proportional hazards model, epidemiology of lymphoid malignancy, epidemiology of primary immunodeficiency diseases and genetic epidemiology family-based. Written by experts from around the globe, this book is reading for clinicians, researchers and students, who intend to address these issues.

\title{
How to reference
}

In order to correctly reference this scholarly work, feel free to copy and paste the following:

Nuno Santos, Margarida Correia-Neves, Virgílio Almeida and Christian Gortázar (2012). Wildlife Tuberculosis: A Systematic Review of the Epidemiology in Iberian Peninsula, Epidemiology Insights, Dr. Maria De Lourdes Ribeiro De Souza Da Cunha (Ed.), ISBN: 978-953-51-0565-7, InTech, Available from:

http://www.intechopen.com/books/epidemiology-insights/wildlife-tuberculosis-a-systematic-review-of-theepidemiology-in-the-iberian-peninsula

\section{INTECH}

open science | open minds

\section{InTech Europe}

University Campus STeP Ri

Slavka Krautzeka 83/A

51000 Rijeka, Croatia

Phone: +385 (51) 770447

Fax: +385 (51) 686166

www.intechopen.com

\section{InTech China}

Unit 405, Office Block, Hotel Equatorial Shanghai

No.65, Yan An Road (West), Shanghai, 200040, China 中国上海市延安西路65号上海国际贵都大饭店办公楼 405 单元

Phone: +86-21-62489820

Fax: $+86-21-62489821$ 
(C) 2012 The Author(s). Licensee IntechOpen. This is an open access article distributed under the terms of the Creative Commons Attribution 3.0 License, which permits unrestricted use, distribution, and reproduction in any medium, provided the original work is properly cited. 